\title{
EFFECTS OF WATERING FREQUENCY AND SOIL TYPES ON SEED GERMINATION AND SEEDLING PERFORMANCE OF LESPEDEZA CYRTOBOTRYA AND DIANTHUS BARBATUS
}

\author{
Ettagbor Hans Enukwa 1,2 (iD) \\ ${ }^{1}$ Department of Civil Engineering and Forestry Techniques, Higher Technical Teacher Training \\ College, University of Bamenda, P.0 Box 39 Bambili, Cameroon \\ 2 Department of Forest Environmental Resources, College of Agriculture and Life Science, \\ Gyeongsang National University, Jinju 528-28, Korea
}

DOI: https://doi.org/10.29121/IJOEST.v4.i5.2020.115

Article Type: Research Article

Article Citation: Ettagbor Hans Enukwa. (2020). EFFECTS OF WATERING FREQUENCY AND SOIL TYPES ON SEED GERMINATION AND SEEDLING PERFORMANCE OF LESPEDEZA CYRTOBOTRYA AND DIANTHUS BARBATUS.

International Journal of Engineering Science Technologies, 4(5), 80-88. https://doi.org/10.29121/IJOEST.v 4.15.2020.115

Received Date: 4 September 2020

Accepted Date: 12 October 2020

Keywords:

Leaf Mold Soil

Merchantable Soil

Seedling Establishment

Survival Rate

Water Regimes

Water Stress

\section{ABSTRACT}

This study was carried out to determine the effect of various watering regimes in different soils on seed germination and seedling establishment for two species (Dianthus Barbatus and Lespedeza cyrtobotrya) The ratio of water used for watering was $16 \mathrm{ml}$ water $/ 100 \mathrm{~g}$ soil. Three watering frequencies (i.e. once daily; once every 2 days; once every 3 days) were applied for two soil types (Leaf mold soil and merchantable soil) for a period of 150 days. The differences in seed germination, seedling survival and seedling growth were monitored in all experimental units. A more regular watering frequency increases soil moisture, and vice versa. The results showed that watering frequency had significant effects on seed germination $(p=0.008)$, number of plant leaves $(p=0.05)$, with visible but statistically insignificant effects on mean plant height $(p=0.19)$ and seedling survival $(\mathrm{p}=0.3)$ for two plant species. The total height of plant species also varied greatly within treatments. Positive correlations were recorded between germination rate with leaf number $(r=0.79, p=0.0001)$; plant height with survival rate $(\mathrm{r}=0.65, \mathrm{p}=0.001)$; plant height with leaf number $(\mathrm{r}=0.77, \mathrm{p}=0.0001)$; survival rate with leaf number $(r=0.66, p=0.0001)$ etc. Seed germination and aboveground heights of D. barbatus and L. cyrtobotrya decreased at the more regular watering frequency of once daily in both soils. On leaf mold soil, the total height and mean height of L. cyrtobotrya decreased with increased water stress at once every 3 days watering frequency. Also, the total height of D. barbatus decreased with increased water stress at once every 3 days watering frequency on this soil, even though its mean height did not decrease. In contrast on merchantable soil, the total height and mean height of L. cyrtobotrya increased with increased water stress at once every 3 days watering frequency, indicating that this plant is more resistant to stress on this soil. Whereas, the total height and mean height of D. barbatus decreased with increased water stress on this soil. On leaf mold soil, once every 2 days watering was the most suitable watering frequency for both species in terms of achieving best seed germination and seedling establishment. In contrast on merchantable soil, once every 3 days watering frequency was most suitable for $\mathrm{L}$. cyrtobotrya, whereas both once every 2 days and once every 3 days watering frequencies were suitable for $\mathrm{D}$. barbatus on this soil. The results suggest that using the required watering frequency and soil type is imperative to ensure sustainability in plant production and seedling establishment. 
Ettagbor Hans Enukwa

\section{INTRODUCTION}

The choice of plant species and climate condition are imperative considerations for the success of ecological restoration (Andres \& Jorda, 2000). Seed germination and seedling growth are critical stages in the life cycle of a plant, and are often subject to high mortality rates (Geraldine and Lisa, 1999). Seed germination and emergence determine the efficient use of the nutrients and water resources available to plants (Gan, 1996; Wojtyla et al. 2016).

Water uptake triggers key biochemical and cellular processes associated with seed germination such as the reactivation of metabolism, resumption of cellular respiration, biogenesis of mitochondria, DNA repair, translation and/or degradation of stored mRNAs, transcription and translation of new mRNAs, and the onset of reserve mobilization (Bentsik and Koornneef, 2008; Nonogaki et al., 2010). Seed germination and seedling growth requirements for plants are vital information needed to facilitate domestication and improvement of their potentials. Seed germination potentials are usually dependent on a combination of environmental conditions (Karssen and Hilhorst, 1992; Carmona and Murdoch, 1995).

Many studies have been carried out and reported on the pretreatment methods of seeds such as soaking seeds in water (Werker, 1980; Yu et al. 2014; Huan et al., 2016), chemical pretreatments such as immersion of seeds in acids (Todd and Duryea, 1993; Edward et al., 2013), soaking seeds in salt solutions (Yu et al. 2014), and treatment with plant growth hormonce, but there is limited information on the adequate watering frequency in different soils to enhance seed germination and seedling growth.

Water is a basic requirement for germination, as it is essential for enzyme activation, breakdown, translocation, and use of reserve storage material (Morad, 2013).

The current research is therefore, designed to investigate the germination of seeds and seedlings growth of Dianthus barbatus and Lesperdeza cyrtobotrya in response to different watering regimes and soils. Lespedeza cyrtobotrya is a deciduous tree of the leguminous family and is distributed in forests at medium and low altitudes. It is a drought-enduring plant, and is highly valued as foliage, green manure crops, or honey resources and also for the prevention of soil erosion (Zhu et al. 2002). Dianthus barbatus is a species of Dianthus native to southern Europe and parts of Asia which has become a popular ornamental garden plant. The seeds of Lespedeza cyrtobotrya and Dianthus barbatus are readily available and widely sold by commercial suppliers. It is hoped that the information gathered would help conservation and domestication of the plant species that could subsequently be used for revegetation of damaged lands.

\section{MATERIALS AND METHODS}

\subsection{SOIL TYPES, SOIL CHARACTERISTICS AND TARGET SPECIES}

Two different soils were used for this experiment including: 1. Leaf mold soil consisting of a mixture of fermented coco peat and decomposed leaves; 2 . Merchantable soil with weathered granite, consisting of a mixture of fermented coco peat, vermiculite, perlite and nutrient solution. The soils were purchased from commercial suppliers.

Physicochemical analysis of the soils showed that Leaf mold soil had the lowest pH of 5.57. For Electrical conductivity, Leaf mold soil had the highest of $13.86 \mathrm{dS} / \mathrm{m}$, while merchantable soil had $8.12 \mathrm{dS} / \mathrm{m}$. Leaf mold soil had the highest soil organic matter content of $20.175 \%$. For total nitrogen content, Leaf mold soil had $12.71 \%$, and Merchantable soil had 7.72\%. Available phosphorus content for Leaf mold soil (204.93 mg/Kg), and Merchantable soil (103.91 mg/Kg). Among the cations, $\mathrm{Ca}, \mathrm{Mg}, \mathrm{K}, \mathrm{Na}$ contents were higher in Leaf mold soil.

A woody plant (Lespedeza cyrtobotrya), and a herbaceous plant (Dianthus barbatus) were used for the experiment.

\subsection{EXPERIMENTAL MATERIALS AND EXPERIMENTAL DESIGN}

Pots were used as experimental units with the pots placed on a slab in the laboratory. Leaf mold soil was filled in 60 pots and Merchantable soil filled in 60 pots. Mature seeds of L. cyrtobotrya and D. barbatus were purchased from commercial seed suppliers and used for the experiment. The sample size used for each watering frequency per soil type was 10 pots for each plant species. 10 seeds for each of the plant species were sowed in each pot with each 
having 10 replicates per watering frequency. Thus, a total of 1200 seeds (i.e. 600 seeds per plant species) were used in the experiment.

\subsection{WATERING OF EXPERIMENTAL POTS}

Watering of the pots was done immediately after sowing using spray irrigation to keep the experiment ongoing. Watering was done between 07:00 am and 09:00 am when it was cool in order to reduce evaporative losses. Tap water, drawn fresh as and when required, was used to irrigate the pots. The required amount of water was filled in the spray can and spraying done accordingly. The ratio of water used for watering was $16 \mathrm{ml}$ water $/ 100 \mathrm{~g}$ soil. Three watering regimes each lasting 120 days were applied: (1) Once daily (2) Once every two days (3) Once every three days. The watering regimes were simulations of seasons were rainfall could be frequent, moderate or far apart.

\subsection{DATA COLLECTION AND ANALYSIS}

The experiment was conducted between the months of February and June. Data were collected on germination rate, survival rate, seedling height, relative growth rate and leaf number. Leaf number was assessed by physical counting. Seedling height was measured with metre rule. The relative growth rates (RGR) were calculated as follows:

$$
\left.\mathrm{RGR} \%=\frac{(\mathrm{Mf} / \mathrm{Mi}}{\Delta \mathrm{T}}-0.05\right) \times 100
$$

Where Mf is the final measurement of the mean stem length, Mi is the initial measurement of the mean stem length, and $\Delta \mathrm{T}$ is the number of months passed between the measurements (Zammith \& Scarano, 2006; Zhong et al., 2009).

Analysis involved a comparison of the measured and calculated parameters of the species by watering regime using two ways ANOVA procedures, with Turkey's Test used $(\mathrm{p}<0.05)$ to test statistical significance of differences between means. All analyses were conducted using SPSS software (23).

\section{RESULTS}

\subsection{THE EFFECT OF WATERING FREQUENCY ON SEED GERMINATION}

The two ways ANOVA showed that watering frequency significantly affected $(\mathrm{p}=0.008)$ seed germination of all two species. On Merchantable soil, seed germination of D. barbatus and L. Cyrtobotrya increased with reduced watering frequency from once daily, to once every 2 days, and to once every 3 days watering (Fig. 1). At a watering frequency of once every 3 days on this soil, $D$. barbatus achieved a germination rate of $90 \%$, and $24.5 \%$ for $L$. cyrtobotrya. On Leaf mold soil, seed germination of D. barbatus increased with reduced watering frequency (from once daily to once every 2 days), and then decreased as watering frequency reduced further (from once every 2 days to once every 3 days). At a watering frequency of once every 2 days on this soil, $D$. barbatus achieved a germination rate of $67 \%$. Also, on Leaf mold soil, seed germination of L. cyrtobotrya increased with reduced watering frequency (from once daily to once every 2 days), and then showed no significant change as watering frequency reduced further (from once every 2 days to once every 3 days), with germination rates of $17 \%$ and $18 \%$ respectively. Merchantable soil with watering frequency of once every 3 days had the highest germination rate for both species. 

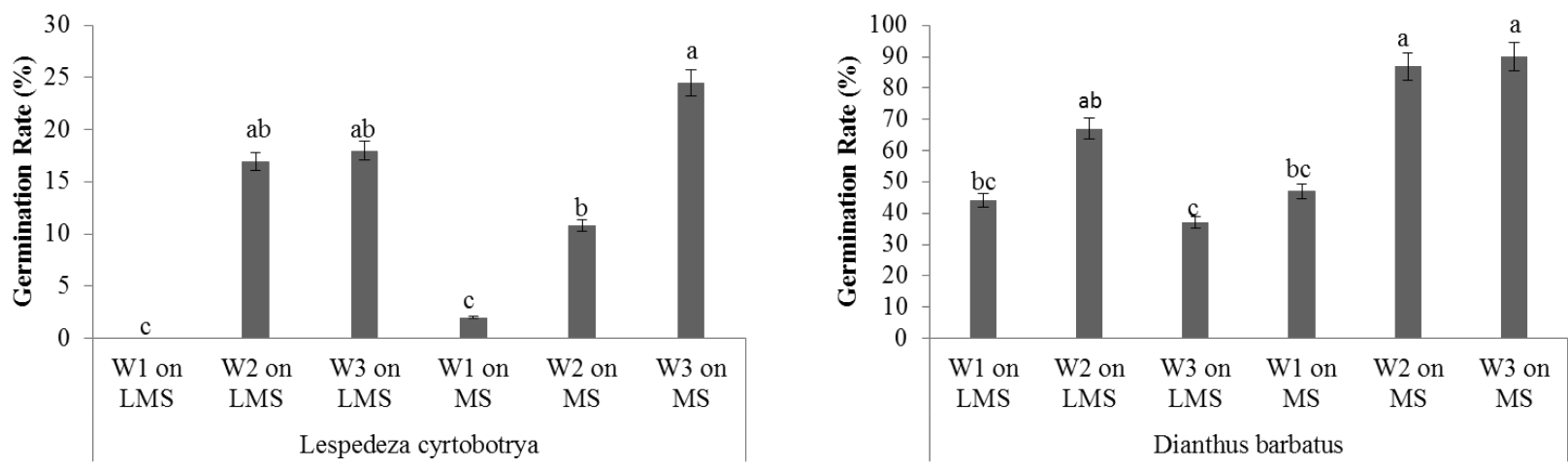

Figure 1: Effects of watering frequency on the seed germination of two species (mean \pm SE). Once daily (W1) (control), Once every 2 days (W2), and Once every 3 days (W3) represent the watering frequencies used for leaf mold soil (LMS) and merchantable soil (MS). The letters above the error bar indicates the level of difference among watering frequencies for each soil type at $\mathrm{p}=0.05$ within each species.

\subsection{THE EFFECT OF WATERING FREQUENCY ON SEEDLING SURVIVAL}

Watering frequency affected seedling survival of all two species, even though the effect was not significant $(\mathrm{p}=0.301)$. On Merchantable soil, seedling survival of D. barbatus and L. Cyrtobotrya decreased with reduced watering frequency from once daily, to once every 2 days, and then increased as watering frequency further reduced to once every 3 days (Fig. 2). At a watering frequency of once every 3 days on this soil, D. barbatus achieved a survival rate of $61 \%$, and $73 \%$ for L. cyrtobotrya, whereas at a watering frequency of once daily, D. barbatus achieved a survival rate of $73 \%$, and $100 \%$ for L. cyrtobotrya. On Leaf mold soil, seedling survival of D. barbatus decreased with reduced watering frequency (from once daily, to once every 2 days, to once every 3 days). At a watering frequency of once daily on this soil, D. barbatus achieved a survival rate of $61 \%$, and $51 \%$ at a watering frequency of once every 2 days. Also, on Leaf mold soil, seedling survival of L. cyrtobotrya decreased with reduced watering frequency (from once every 2 days to once every 3 days), with survival rates of $41.2 \%$ and $28 \%$ respectively.
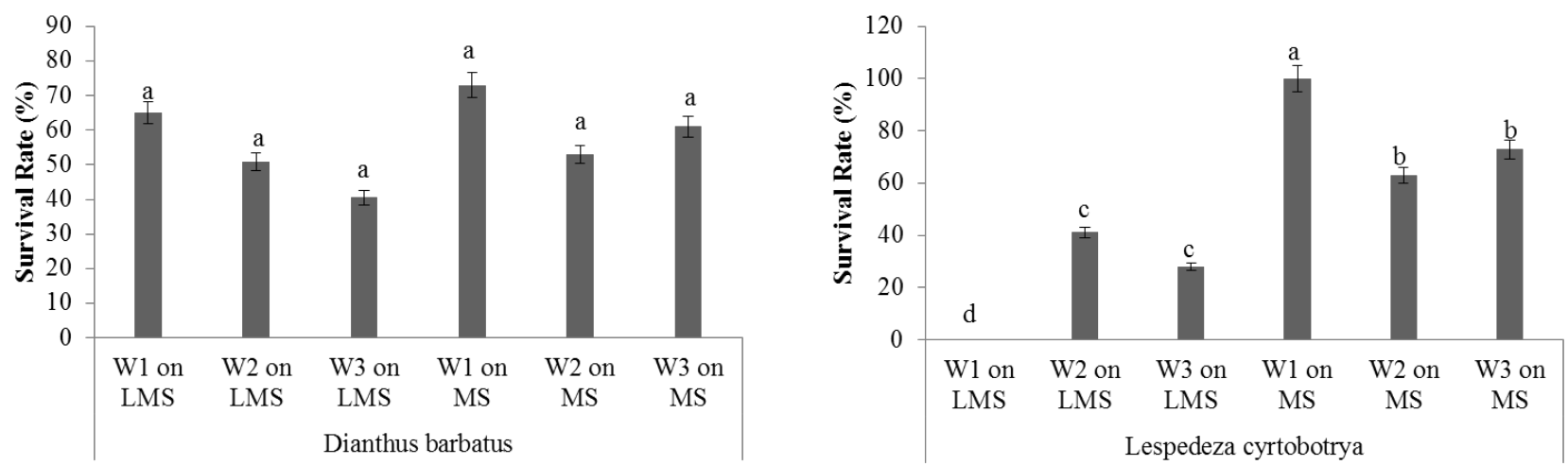

Figure 2: Effects of watering frequency on the seedling survival of two species (mean \pm SE). Once daily (W1) (control), Once every 2 days (W2), and Once every 3 days (W3) represent the watering frequencies used for leaf mold soil (LMS) and merchantable soil (MS). The letters above the error bar indicates the level of difference among watering frequencies for each soil type at $\mathrm{p}=0.05$ within each species.

\subsection{SEEDLING LEAF NUMBER}

Watering frequency significantly affected $(\mathrm{p}=0.05)$ the number of plant leaves for all two species. On Merchantable soil, the number of leaves of L. Cyrtobotrya increased with reduced watering frequency from once daily, to once every 2 days, and to once every 3 days watering (Fig. 3), whereas on this same soil the number of leaves for $D$. barbatus increased with decreased watering frequency (from once daily to once every 2 days), and then reduced as watering frequency further decreased to once every 3 days. At a watering frequency of once every 3 days 
on this soil, L. cyrtobotrya achieved a mean of 17.7 leaves, and 26.5 leaves for D. barbatus at watering frequency of once every 2 days. On Leaf mold soil, the number of leaves of D. barbatus and L. cyrtobotrya increased with reduced watering frequency (from once daily to once every 2 days), and then decreased as watering frequency reduced further (from once every 2 days to once every 3 days). At a watering frequency of once every 2 days on this soil, $D$. barbatus achieved a mean of 24.4 leaves, and 16.1 leaves for L. cyrtobotrya.
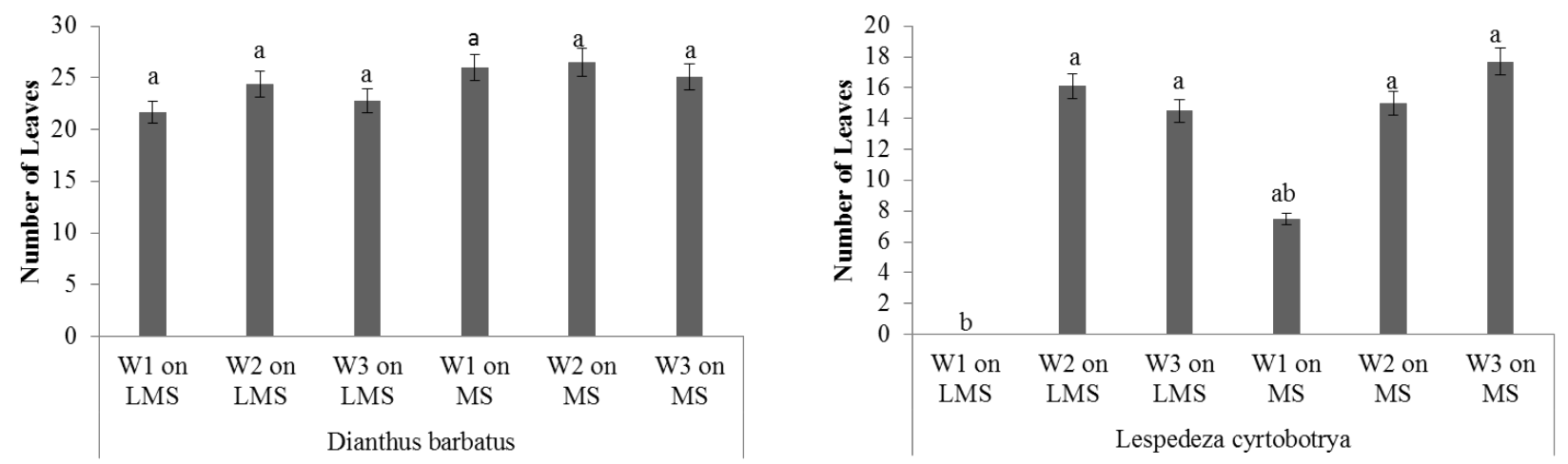

Figure 3: Effects of watering frequency on the number of leaves for two species (mean \pm SE). Once daily (W1) (control), Once every 2 days (W2), and Once every 3 days (W3) represent the watering frequencies used for leaf mold soil (LMS) and merchantable soil (MS). The letters above the error bar indicates the level of difference among watering frequencies for each soil type at $\mathrm{p}=0.05$ within each species.

\subsection{THE EFFECT OF WATERING FREQUENCY ON SEEDLING HEIGHT}

Watering frequency affected the aboveground height of seedlings for all two species, even though the effect was not significant ( $\mathrm{p}=0.19$ ). On Merchantable soil, seedling height of L. Cyrtobotrya increased with increased watering frequency from once daily, to once every 2 days, and to once every 3 days watering (Fig. 4). Also, on this soil, the aboveground height of $D$. barbatus increased as the watering frequency decreased from once daily to once every 2 days, but reduced as watering frequency further decreased to once every 3 days. At a watering frequency of once every 3 days on this soil, L. cyrtobotrya achieved mean height of $14.5 \mathrm{~cm}$, and $14.1 \mathrm{~cm}$ for D. barbatus at once every 2 days watering frequency. On Leaf mold soil, aboveground height of $D$. barbatus increased with reduced watering frequency. At a watering frequency of once every 2 days on this soil, $D$. barbatus achieved aboveground height of $14.5 \mathrm{~cm}$, and 14.9 at a watering frequency of once every 3 days. Also, on Leaf mold soil, the aboveground height of $L$. cyrtobotrya decreased with reduced watering frequency (from once every 2 days to once every 3 days), with mean heights of $13.8 \mathrm{~cm}$ and $11.5 \mathrm{~cm}$ respectively.
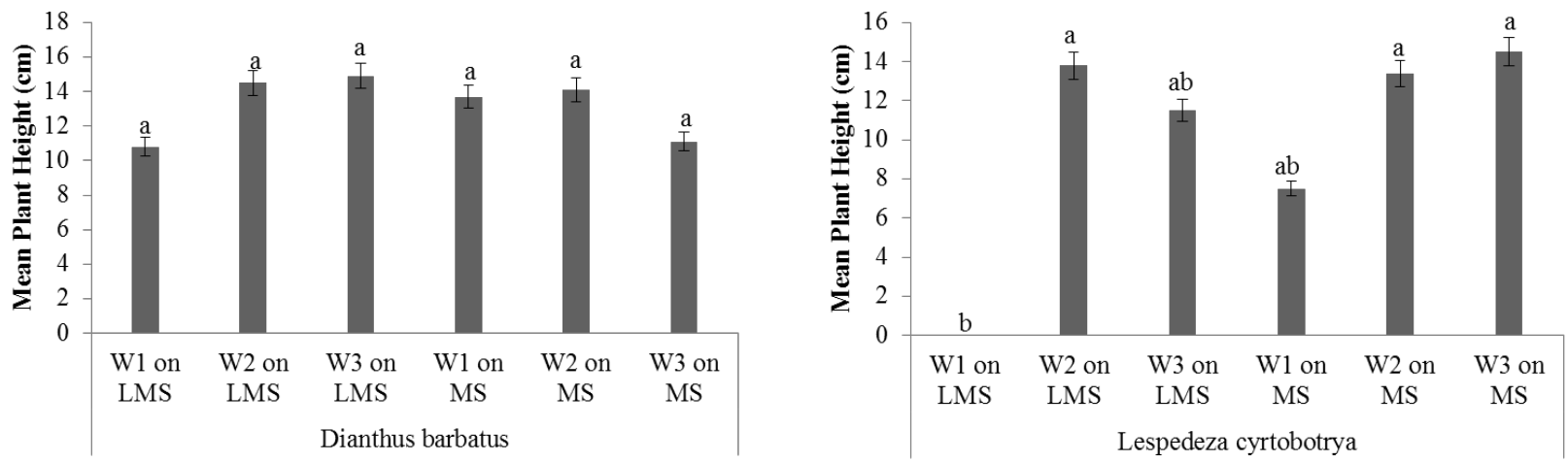

Figure 4: Effects of watering frequency on the seedling height (aboveground height) for two species (mean \pm SE). Once daily (W1) (control), Once every 2 days (W2), and Once every 3 days (W3) represent the watering frequencies used for leaf mold soil (LMS) and merchantable soil (MS). The letters above the error bar indicates the level of difference among watering frequencies for each soil type at $p=0.05$ within each species. 
Watering frequency also affected the total aboveground height of seedlings for all two species. On Merchantable soil, total seedling height of L. Cyrtobotrya increased with decreased watering frequency from once daily, to once every 2 days, and to once every 3 days (Fig. 5). Also, on this soil, the total aboveground height of D. barbatus increased as the watering frequency decreased from once daily to once every 2 days, but reduced as watering frequency further decreased to once every 3 days. At a watering frequency of once every 3 days on this soil, L. cyrtobotrya achieved total height of $231 \mathrm{~cm}$, with $651 \mathrm{~cm}$ and $625 \mathrm{~cm}$ for D. barbatus at once every 2 days and once every 3 days watering frequencies respectively. On Leaf mold soil, the total aboveground height of $D$. barbatus increased with reduced watering frequency (from once daily, to once every 2 days), and then reduced as watering frequency further reduced to once every 3 days. At a watering frequency of once every 2 days on this soil, D. barbatus achieved total aboveground height of $449 \mathrm{~cm}$. Also, on Leaf mold soil, the total aboveground height of L. cyrtobotrya decreased with reduced watering frequency (from once every 2 days to once every 3 days). L. cyrtobotrya achieved a total height of $97 \mathrm{~cm}$ on this soil at the once every 2 days watering frequency.
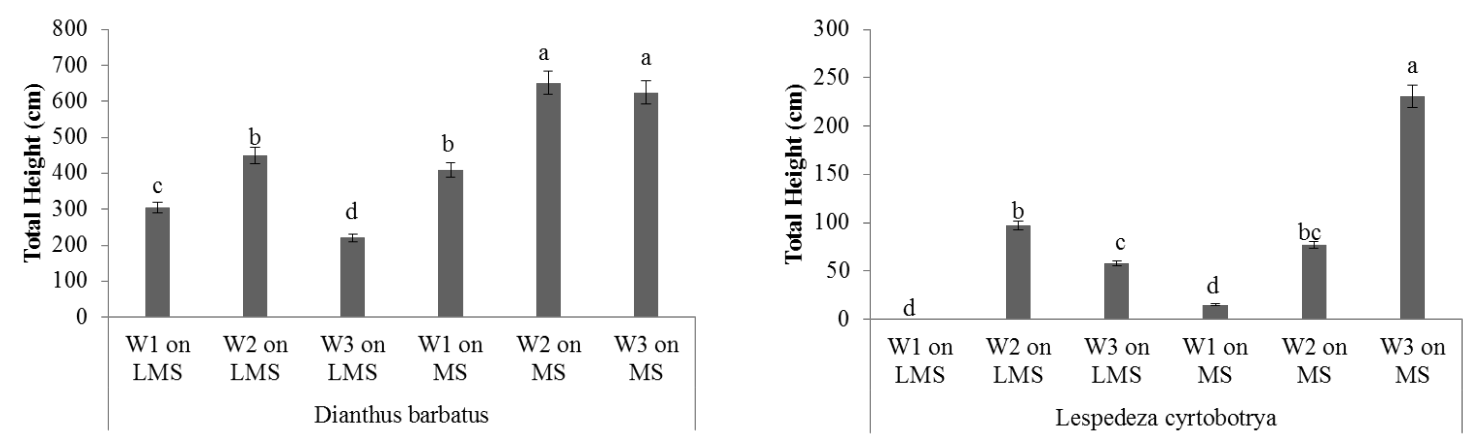

Figure 5: Effects of watering frequency on the total height (aboveground height) for two species. Total height represents the sum of heights for all the plants. Once daily (W1) (control), Once every 2 days (W2), and Once every

3 days (W3) represent the watering frequencies used for leaf mold soil (LMS) and merchantable soil (MS). The letters above the error bar indicates the level of difference among watering frequencies for each soil type at $\mathrm{p}=$ 0.05 within each species.

\subsection{THE EFFECT OF WATERING FREQUENCY ON SEEDLING RELATIVE GROWTH RATE (RGR)}

Watering frequency also affected the Relative Growth Rate (RGR) of seedlings for all two species. On Merchantable soil, RGR of L. Cyrtobotrya and D. barbatus increased with decreased watering frequency (from once daily, to once every 2 days), and then reduced as watering frequency further decreased to once every 3 days (Fig. 6). At a watering frequency of once every 2 days on this soil, L. cyrtobotrya achieved RGR of $94.3 \%$, and $133.2 \%$ for $D$. barbatus. On Leaf mold soil, the RGR of D. barbatus and L. Cyrtobotrya increased with reduced watering frequency. At a watering frequency of once every 3 days on this soil, D. barbatus achieved RGR of $172.4 \%$, and $101.5 \%$ for $L$. cyrtobotrya.
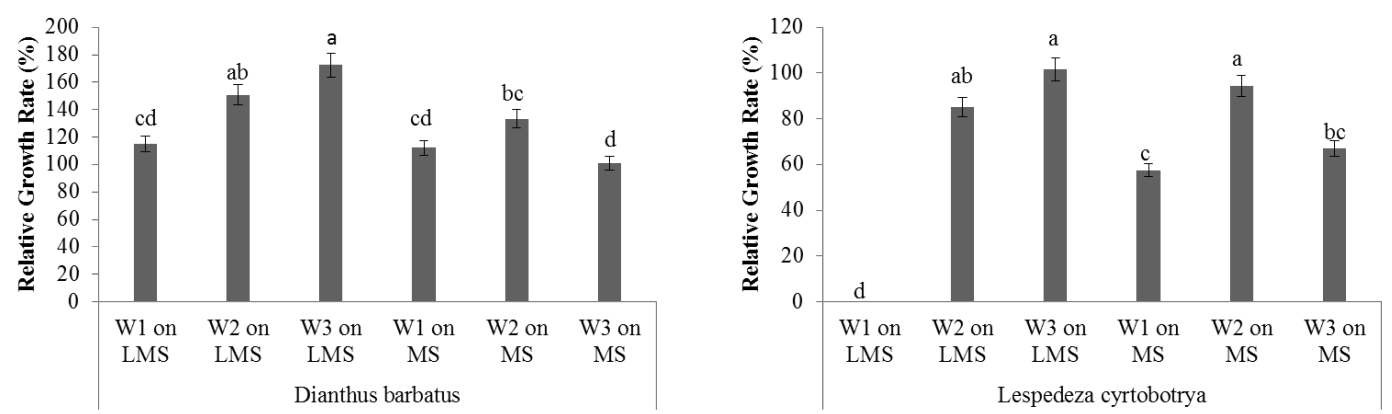

Figure 6: Effects of watering frequency on the relative growth rates (\%) of two species (mean \pm SE). Once daily (W1) (control), Once every 2 days (W2), and Once every 3 days (W3) represent the watering frequencies used for leaf mold soil (LMS) and merchantable soil (MS). The letters above the error bar indicates the level of difference among watering frequencies for each soil type at $\mathrm{p}=0.05$ within each species. 
Effects of Watering Frequency and Soil Types on Seed Germination and Seedling Performance of Lespedeza Cyrtobotrya and Dianthus Barbatus

\section{DISCUSSION}

The efficient progression of germination determines the nature of seedling establishment and the proper development of mature plants (Wojtyla et al. 2016). The initial step in germination is the imbibition of water by the various tissues within the seed. This enables the embryo to break through the softened seed coat and renders the seed coat more permeable to gases, so that respiration can proceed (Meyer and Donald, 1952).

The amount of water provided to the soil influence seed germination and seedling establishment (Tylor et al., 1982), but there is limited information on the favorable watering frequency for seed germination and plant growth. The germination and growth of different plant species also vary with respect to soil types and watering frequencies. Stiles (1948) reported that seed germination varies with varieties, as seed coats of different seeds have different absorption capacities of water.

Generally in this study, some measured parameters showed positive correlations with each other such as: germination rate with leaf number $\left(r=0.790^{* *}, p=0.000\right)$; plant height with survival rate $\left(r=0.651^{* *}, p=0.001\right)$; plant height with leaf number $\left(\mathrm{r}=0.774^{* *}, \mathrm{p}=0.000\right)$; survival rate with leaf number $(\mathrm{r}=0.657, \mathrm{p}=0.000)$ etc.

This study showed that seed germination and aboveground heights of D. barbatus and L. cyrtobotrya decreased at the more regular watering frequency of once daily, both in the Leaf mold soil and Merchantable soil. This result is similar to that obtained by Dasberg and Mendel (1971) who reported that at high soil moisture, germination of Oryzopsis holciformis decreased. More regular watering of once daily thus provided high soil moisture, which reduced seed germination. This decrease in germination could be as a result of the thickening of the water films around the seeds, which interfered with oxygen diffusion.

On Leaf mold soil, the total height and mean height of L. cyrtobotrya decreased with increased water stress at once every 3 days watering frequency. These results agreed with that of Momen et al. (1979); Lutfor and Mesbah (2000); Majnoun et al. (2009) who reported decrease in plant height with more severe soil moisture deficits. Similarly, the total height of D. barbatus decreased with increased water stress at once every 3 days watering frequency on this soil, even though its mean height did not decrease. Water stress results in depression of plant height (Nielsen and Nelson, 1998; Shenkut and Brick, 2003; Mannan et al. 2016) especially in soils that easily become dry and hardened as it is the case for Leaf mold soil. Also, reduced soil moisture during the early seedling stage diminishes growth which in turn would result in a reduction of yield (Constable and Hern, 1978). It affects both elongation and expansion growth (Anjum et al., 2003; Shao et al., 2008). Thus, the decrease in plant height on this soil with time could be as a result of the fact that the top soil easily got dried and hardened over time thus reducing the amount of water and dissolved nutrients for uptake by the seedlings.

On Merchantable soil, the total height and mean height of L. cyrtobotrya instead increased with increased water stress at once every 3 days watering frequency, indicating that this plant is more resistant to stress on this soil. Contrarily, the total height and mean height of D. barbatus decreased with increased water stress at once every 3 days watering frequency on this soil.

Generally, the survival rates of both species reduced in treatments that had higher germination rates especially on Merchantable soil. This could be as a result of the fact that with increased germination, more seedlings were available in the soil, thus resulting to increased competition for soil nutrients and eventual death of some weaker seedlings. However, on leaf mold soil, increased water stress (once every 3 days watering frequency) resulted to lower survival rates of both L. cyrtobotrya and D. barbatus. Severe water stress may affect photosynthesis, disturb metabolism and finally result to plant death (Jaleel et al., 2008).

This study showed that generally on Leaf mold soil, once every 2 days watering is the suitable watering frequency for many plant species in terms of achieving best seed germination and seedling establishment. Thus, on this soil, high soil moisture (once daily watering frequency) and very low soil moisture (once every 3 days watering frequency) discourages seed germination and seedling establishment.

Contrarily on Merchantable soil, once every 3 days watering is the suitable watering frequency for L. cyrtobotrya in terms of achieving best seed germination and seedling establishment, whereas both 2 days and 3 days watering frequencies tend to be suitable for $D$. barbatus on this soil.

Watering frequency is thus an important determinant in soils for seed germination and seedling establishment, as it has a direct contribution to the adequate or required amount of soil moisture.

The results provide enough proof for the selection of species and soils, as well as the determination of the watering frequency, with regards to seed germination and seedling establishment. 


\section{CONCLUSION}

Watering frequency significantly affects seed germination and seedling establishment on different soil types. Generally, once every 2 days watering frequency is appropriate for seed germination and seedling establishment for most species on Leaf mold soil. Thus, more frequent watering (once daily watering frequency) and increased water stress (once every 3 days watering frequency) on this soil discourages seed germination and seedling establishment. Therefore, soils that easily get dried and hardened can be more productive only in conditions of moderate soil moisture. Contrarily, once every 3 days watering frequency is appropriate for seed germination and seedling establishment on Merchantable soil. Both L. cyrtobotrya and D. barbatus performed well on this soil at the once every 3 days watering frequency. The once every 2 days watering frequency is also adequate for germination and restoration of $D$. barbatus on this soil. This indicates that plants tend to be more resistant on soils that have a good drainage and do not easily become hardened, but have the potential of retaining moisture for a considerable period.

Tree plants (L. cyrtobotrya) appeared to perform poorly in conditions of high moisture both on Leaf mold soil and Merchantable, and also in conditions of water stress (once every 3 days watering frequency) on Leaf mold soil. Contrarily, herbaceous plants (D. barbatus) performed better than L. cyrtobotrya on these conditions.

\section{SOURCES OF FUNDING}

This research received no specific grant from any funding agency in the public, commercial, or not-for-profit sectors.

\section{CONFLICT OF INTEREST}

The author have declared that no competing interests exist.

\section{ACKNOWLEDGMENT}

This research did not receive any specific grant from funding agencies in the public, commercial, or not-forprofit sectors.

\section{REFERENCES}

[1] Andres, P. and Jorba, M. 2000. Mitigation strategies in some motorway embankments (Catalonia Spain). Restoration Ecology 8:268-275.

[2] Anjum, F., Yaseen, M., Rasool, E., Wahid, A. and Anjum, S. 2003. Water stress in barley (Hordeum vulgare L.). I. Effect on morphological characters. Pakistan Journal of Agricultural Sciences 40: 43-44.

[3] Bentsik, L., and Koornneef, M. 2008. Seed dormancy and germination. Arabidopsis Book 6, e0119. doi: 10.1199/tab.0119.

[4] Carmona, R. and Murdoch, A.J. 1995. Interactions of temperature and dormancy - relieving compounds on the germination of weed seeds. Seed Science Research 5: 227-236

[5] Constable, G.R. and Hern, A.B. 1978. Agronomic and Physiological Responses of Soybean and Sorghum Crops to Water Deficits. I. Growth, Development and Yield. Australian Journal of Plant Physiology 5: 159-167.

[6] Dasberg, S. and Mendel, K. 1971. The Effect of Soil Water and Aeration on Seed Germination. Journal of Experimental Botany 22 (4): 992-998. doi: 10.1093/jxb/22.4.992

[7] Edward, M., Chikumbutso, M., Dackious, K., Hannah, B. and Gift, K. 2013. Effect of Seed Size and Pretreatment Methods on Germination of Albizia lebbeck, Article ID 969026. http://dx.doi.org/10.1155/2013/969026.

[8] GAN, Y. 1996. Evaluation of select nonlinear regression models in quantifying seedling emergence rate of spring wheat. Crop Science 36:165-168.

[9] Geraldine, L.D. and Lisa A.D. 1999. Water potential and ionic effects on germination and seedling growth of two cold desert shrubs. American Journal of Botany 86(8): 1146-1153. 
Effects of Watering Frequency and Soil Types on Seed Germination and Seedling Performance of Lespedeza Cyrtobotrya and Dianthus Barbatus

[10] Huan, M., Xuehong, W., Shouzheng, T., Xianguo, L., Mingxu, H., Yu, A. and Zhongsheng, Z. 2016. Seed germination environments of Typha latifolia and Phragmites australis in wetland restoration. Ecological Engineering. Article in press

[11] Jaleel, C.A., Manivannan, P., Lakshmanan, G.M.A., Gomathinayagam, M. and Panneerselvam, R. 2008. Alterations in morphological parameters and photosynthetic pigment responses of Catharanthus roseus under soil water deficits. Colloids and Surfaces B: Biointerfaces. 61: 298-303.

[12] Karssen, C.M., Hilhorst, H.W.M. 1992. Effect of chemical environment on seed germination. pp 327-348 in Fenner, M. (Ed.) Seeds. The ecology of regeneration in plant communities. Wallingford, UK, CAB International.

[13] Lutfor, R.S.M. and Mesbah, U.A.S. M. 2000. Ecological Adaptation of Chickpea (Cicer arietinum L.) to Water Stress. II. Grain Yield, Harvest Index, Flowering and Maturity Studies. Legume Research 23 (1): 1-8.

[14] Majnoun, H.N., Siddique, K.H.M., Palta, J.A. and Berger, J. 2009. Effect of Soil Moisture Content on Seedling Emergence and Early Growth of Some Chickpea (Cicer arietinum L.) Genotypes. Journal of Agricultural Science Technology 11: 401-411

[15] Mannan, M.A., Halder, E., Karim, M.A. and Ahmed, J.U. 2016. Alleviation of Adverse Effect of Drought Stress on Soybean (Glycine max. L.) by Using Poultry Litter Biochar. Bangladesh Agronomy Journal 19(2): 61-69.

[16] Meyer, B.S., and Donald, B.A. 1952. Plant physiology. 2nd ed. New York: D. Van Mostrand Company, Inc. 784 pp.

[17] Momen, N.N., Carlson, R.E., Shaw, R.H. and Arjmend, O. 1979. Moisture Stress Effects on Yield Components of Two Soybean Cultivars. Agronomy Journal 71: 86-90.

[18] Morad, S., 2013. Effect of water and temperature on seed germination and emergence as a seed hydrothermal time model. International journal of Advanced Biological and Biomedical Research 12: 1686-1691.

[19] Nielsen, D.C. and Nelson, N.O. 1998. Black bean sensitivity to water stress at various growth stage. Crop Science 38: 422-427.

[20] Nonogaki, H., Bassel, G.W., and Bewley, J.D. 2010. Germination - still a mystery. Plant Science 179: 574-581. doi: 10.4161/psb.25504.

[21] Shao, H.B., Chu, L.Y., Jaleel, C.A. and Zhao, C.X. 2008. Water deficit stressinduced anatomical changes in higher plants. Comptes Rendus Biologies 331: 215-225.

[22] Shenkut, A.A. and Brick, M.A. 2003. Traits components in common bean associated Alleviation of Adverse Effect of Drought Stress on Soybean (Glycine max. L.) By Using Poultry Litter Biochar with dry edible bean (Phaseolus vulgaris L.) productivity under diverse soil moisture environments. Euphytica 133: 339-347.

[23] Stiles, I.E. 1948. Relation of water to the germination of corn and cotton seeds. Plant Physiology 23: 201-222.

[24] Todd-Bockarie, A.H. and Duryea, M.L. 1993. Seed pretreatment methods to improve germination of the multipurpose West African forest species Dialium guineense. Forest Ecology and Management 57:257-273

[25] Tylor, A.G., Motes, J.E. and Kirkham, M.B. 1982. Germination and Seedling Growth Characteristics of Three Tomato Species Affected by Water Deficits. Horticulture Journal 107: 282-285.

[26] Werker, E., 1980. Seed dormancy as explained by the anatomy of embryo envelopes. Israel Journal of Botany 29: 22-44.

[27] Wojtyla, Ł., Lechowska, K., Kubala, S. and Garnczarska, M. 2016. Different Modes of Hydrogen Peroxide Action During Seed Germination. Frontiers in Plant Science 7:66. doi: 10.3389/fpls.2016.00066

[28] Yu, T., Bo, G., Daowei, Z., Junbao, Y., Guangdi, L. and Yujie, L. 2014. Responses of Seed Germination, Seedling Growth, and Seed Yield Traits to Seed Pretreatment in Maize (Zea mays L.). The Scientific World Journal, ID 834630. http://dx.doi.org/10.1155/2014/834630

[29] Zammith, L.R., Scarano, F.R. 2006. Restoration of a restinga sandy coastal plain in Brazil: survival and growth of planted woody species. Restoration Ecology 14: 87-94.

[30] Zhong, Q.C., Liang, H.W. and Ting, T.L. 2009. Revegetation of steep rocky slopes: Planting climbing vegetation species in artificially drilled holes. Ecological Engineering 35: 1079-1084. http://dx.doi.org/10.1016/j.ecoleng.2009.03.021

[31] Zhu, Y.Y., Feng, L.K., En, T.W., Ge, H.W. and Wen, X.C. 2002. Characterization of rhizobia that nodulate legume species of the genus Lespedeza and description of Bradyrhizobium yuanmingense sp. nov. International Journal of Systematic and Evolutionary Microbiology 52: 2219-2230. 